\title{
TECNOLOGIAS DIGITAIS NA EDUCAÇÃO BÁSICA: desafios e possiblidades
}

\author{
Mariangela Kraemer Lenz Ziede - UNIARP - mariangela.ziede@uniarp.edu.br \\ Ezequiel Theodoro da Silva - UNIARP - silvasilva1948@gmail.com \\ Ludimar Pegoraro - UNIARP - pegoraro1963@hotmail.com \\ Edilson Marino Canalle - UNIARP - edilson@uniarp.edu.br \\ Andreza de Oliveira Meireles da Silva - UNIARP - andreza2308@hotmail.com \\ Aline Fernanda Wodonos de Carvalho - UNIARP - aline.fernanda.15@hotmail.com
}

\begin{abstract}
Resumo: O objetivo geral deste estudo é analisar como os professores da educação básica das escolas de Caçador/SC estão utilizando as tecnologias digitais da informação e comunicação nas suas práticas pedagógicas. Para a coleta dos dados foi construído um questionário no Google.docs e enviado aos professores das escolas. A análise dos dados foi realizada a partir de cinco categorias: i) apropriação das TDIC pelos professores da educação básica: ii) A utilização das TDIC como parte integrante no Projeto Político Pedagógico da escola; iii) a inserção das tecnologias nos projetos dos professores; iv) a contribuição das tecnologias para os processos de ensino e aprendizagem; e v) os desafios de utilização das TDIC pelos professores nas escolas. Concluímos que os professores vivenciam desafios constantes para integrar a tecnologia no currículo com propostas que privilegiem a autoria, a cooperação e o trabalho em rede. É muito importante, portanto, a valorização das experiências e da reflexão sobre a prática, para oportunizar aos professores uma tomada de consciência de que o processo educativo deve ser constantemente pensado e repensado, pois ele é dinâmico e não estático, e que os alunos utilizam as TDIC no seu dia-a-dia, razão pela qual elas precisam ser incorporadas nas práticas escolares.
\end{abstract}

Palavras-chave: Educação básica; tecnologias digitais; práticas pedagógicas

\section{DIGITAL TECHNOLOGIES IN BASIC EDUCATION: challenges and possibility}

\begin{abstract}
The aim of this study is to analyze how the basic education teachers from Caçador / SC schools are using digital technologies of information and communication in their teaching practices. To collect the data it was organized a questionnaire in Google.docs and sent to teachers in schools. Data analysis was carried out from five categories: i) ownership of TDIC by basic education teachers: ii) the use of TDIC as part of the school Pedagogical Political Project; iii) the integration of technologies in the teachers' projects; iv) the contribution of technology for teaching and learning processes; and v) the challenges of using TDIC by teachers in schools. We concluded that teachers experience constant challenges to integrate technology into the curriculum with goals that emphasize the authorship, cooperation and networking. It is very important, therefore, the valuation of experiences and reflection on practice, to create opportunities for teachers an awareness that the educational process must be constantly thought and rethought because it is dynamic and not static, and that the students use the TDIC in their day-to-day life that is the reason why they need to be incorporated into school practices.

Keywords: Basic education; digital technologies; pedagogical practices
\end{abstract}




\section{Introdução}

Não resta dúvida de que as múltiplas discussões sobre a relação entre educação e uso das tecnologias produzem um efeito positivo para a conquista de uma escola de melhor qualidade. De fato, considerando o contexto geral das transformações sociais, nestas últimas três décadas a tecnologia foi fortemente integrada nas nossas vidas, e o impacto maior ocorreu na esfera do acesso à informação disponível na web. Tal mudança diretamente afetou as maneiras de se "fazer educação", sendo mais do que comum, hoje em dia, acompanhar na mídia entrevistas, reflexões e depoimentos de educadores a respeito da inserção, cada vez mais crescente, de laptops, tablets, celulares e outros recursos tecnológicos em sala de aula.

Um estudo realizado em 2015 pelo Ibope Inteligência e Fundação Lemann ouviu mil professores de Ensino Fundamental da rede pública de todo o país, revelando que a grande maioria deles acredita que a tecnologia utilizada em sala de aula pode melhorar a Educação. Disponibilizar materiais didáticos digitais de qualidade e receber formação para o uso da tecnologia aplicada à aprendizagem são objetivos apoiados por $92 \%$ dos professores entrevistados; $81 \%$ acreditam na possibilidade de se conseguir aprendizagem personalizada a partir desses recursos. Percentuais tão altos muito provavelmente decorrem da percepção mais nítida dos professores de que os instrumentos digitais, em seus diferentes suportes e formatos, são os preferidos - e certamente os mais usados pelos estudantes de educação básica nos dias atuais.

De acordo com a pesquisa realizada pelo Centro Regional de Estudos para o Desenvolvimento da Sociedade da Informação.

A maior parte dos professores de escolas públicas declara que aprende sozinho a utilizar computador e Internet $(67 \%)$. A proporção daqueles que fizeram cursos de formação específicos sobre as TIC é menor (57\%). Entre os profissionais que fizeram cursos, a grande maioria (74\%) pagou por ele, em comparação às oportunidades de capacitação oferecidas por secretarias de educação ou outros órgãos de governo (29\%). O Ensino Superior tem ainda um papel a ser explorado nessa questão: $37 \%$ dos docentes de escolas públicas com formação universitária declaram que cursaram uma disciplina específica sobre o uso do computador e da Internet durante a graduação (TIC Educação, 2014, p. 29).

Existe um longo caminho a seguir em relação à formação dos professores. $\mathrm{O}$ governo disponibiliza as tecnologias para as escolas e muitas vezes não disponibiliza formação para a utilização dessas novas ferramentas. Como se pode perceber na pesquisa feita pela TIC Educação em 2014, os professores que têm algum conhecimento sobre tecnologia devem-no a uma pequena demonstração que tiveram na graduação.

Kenski (2014, p. 14) assinala que

O ambiente virtual, em muitos casos, assume poderes e domínios em relação ao docente que os ameaça e os diminui. Inversão total do processo educativo, a 'tecnologia' é mais importante do que o processo que leva à aprendizagem. Na solidão de suas relações com técnicos e tecnologias, o professor submerge e se submete.

Enquanto equipe de investigação, defendemos a necessidade de, durante a sua formação inicial ou através da sua formação continuada ou em serviço, aos professores sejam oferecidos programas atualizados e inovadores relacionados às Tecnologias digitais 
da informação e comunicação (TDIC). A exigência de um processo contínuo de desenvolvimento nessa área justifica-se plenamente em decorrência das circunstâncias que determinam a vida de hoje e das perspectivas para o futuro, das quais podemos destacar o crescimento acelerado dos conhecimentos científicos, técnicos e tecnológicos colocados à disposição da sociedade. E não nos resta dúvida de que os nossos comportamentos são significativamente influenciados pelo volume exponencial de informações disponíveis online e o crescimento do tempo que as pessoas passam lendo e se atualizando através da mídia eletrônica.

Com base nesses dados de realidade, ou seja, de que as tecnologias digitais estão presentes no dia-a-dia dos estudantes, o objetivo geral deste estudo se voltou à análise de como os professores da educação básica das escolas de Caçador/SC estão utilizando TDIC nas suas práticas pedagógicas. Teve como objetivos específicos: verificar os novos significados dos papéis do professor, no que concerne à sua função de mediador e orientador da aprendizagem na educação básica; avaliar se os professores estão utilizando os recursos informáticos na escola, privilegiando a aprendizagem baseada na construção cooperativa de conhecimento.

Nesta perspectiva, a utilização das tecnologias como instrumentos didáticos em sala de aula possibilita ao professor uma nova metodologia de ensino, contribuindo de maneira significativa para o aprendizado dos estudantes.

\section{Educação e tecnologias digitais da informação e comunicação}

Nas últimas décadas houve muitas discussões a respeito da educação e os novos paradigmas de aprendizagem, porém silenciosamente os nativos digitais adotaram a tecnologia e desenvolveram estratégias de aprendizagem e de relacionamento com seus pares.

As tecnologias digitais oferecem à escola possibilidades de desenvolver projetos que promovam a interação com a comunidade em torno da construção do conhecimento, exige que o professor crie propostas que permitam transformar os processos de ensino e de aprendizagem em algo dinâmico e desafiador. Não se trata apenas de adaptar o modelo de escola tradicional as novas ferramentas, logo "[...] novas tecnologias e velhos hábitos de ensino não combinam" (KENSKI, 2003, p. 75).

No documento "Elementos conceituais e metodológicos para definição dos direitos de aprendizagem e desenvolvimento do ciclo de alfabetização do ensino fundamental" (BRASIL, 2012), podemos observar que a utilização das TDIC na educação básica está prevista em muitos de seus objetivos. E também traz um outro conceito de escrita para a escola, a escrita hipertextual, utilizando a tela, o teclado e o mouse ao invés de lápis e papel, possibilitando modificações no próprio processo mental do estudante. Tais mudanças estão previstas pelo MEC, mas será que os professores realmente estão utilizando a tela e o teclado? Todas as escolas têm computadores funcionando? A formação de professores contempla o uso das TDIC?

Corroborando esta ideia, Moran afirma

Desafios e atividades podem ser dosados, planejados e acompanhados e avaliados com apoio de tecnologias. Os desafios bem planejados contribuem para mobilizar as competências desejadas, intelectuais, emocionais, pessoais e comunicacionais. Exigem pesquisar, avaliar situações, pontos de vista 
diferentes, fazer escolhas, assumir alguns riscos, aprender pela descoberta, caminhar do simples para o complexo (MORAN,2015, p.18).

Neste sentido, é muito importante que os professores, durante as suas formações, tenham experiências práticas em atividades que posteriormente poderão ser trabalhadas com seus estudantes. Dessa forma perderão o medo e tomarão consciência das possibilidades de utilização nas suas práticas pedagógicas.

O que a tecnologia traz hoje é integração de todos os espaços e tempos. O ensinar e aprender acontece numa interligação simbiótica, profunda, constante entre o que chamamos mundo físico e mundo digital. Não são dois mundos ou espaços, mas um espaço estendido, uma sala de aula ampliada, que se mescla, hibridiza constantemente (MORAN,2015 p.16).

Acordando com a ideia do Moran, apontamos a necessidade de os professores utilizarem teorias de aprendizagem abertas, que envolvam novas formas de ensinar e aprender, aumentando a autonomia e o protagonismo dos alunos, fazendo parte de uma "Ecologia Cognitiva". Este termo foi definido por Levy (1993) como a disciplina que se dedica ao estudo sistemático da tecnologia informática na organização institucional das sociedades humanas. A ecologia cognitiva pode ser definida como as relações, interações e diálogos instituídos entre diferentes sujeitos que possibilitam a construção de conhecimento.

Segundo Maçada, Sato e Maraschin (2001), a "Ecologia Cognitiva" e as maneiras pelas quais aprendemos estão relacionadas tanto com as conexões da tecnologia quanto com as instituições sociais.

\begin{abstract}
A ideia é que cada ecologia cognitiva - a rede atualizada de relações entre os sujeitos, tecnologias e instituições - produz regimes cognitivos diferenciados. Um dos intuitos em estudos em uma perspectiva ecológica é buscar compreender, a partir das relações contingentes dos sujeitos com as tecnologias e as instituições, os modos de aprender. O conhecimento construído é compreendido com base nas relações constituídas por/em uma comunidade (MAÇADA, SATO E MARASCHIN, 2001, p. 3).
\end{abstract}

Disponibilizar a tecnologia para os professores e alunos não basta, é necessário que sejam feitas discussões sobre os processos de ensino e aprendizagem, o trabalho cooperativo e a utilização de ambiente digitais que promovam a autoria e o trabalho em rede.

\title{
3. Caminhos metodológicos da pesquisa
}

Conhecer é negociar, trabalhar, discutir debater-se com o desconhecido que se reconstitui incessantemente porque toda a solução produz nova questão (MORIN, 2005, p. 104).

Para a coleta dos dados, foi construído um questionário online utilizando o Google.docs com questões mescladas em objetivas e subjetivas. Houve um primeiro contato com as diretoras das escolas e posteriormente com os professores para o envio do questionário. Foram analisados também o projeto Político Pedagógico de duas escolas. 
Uma escola municipal que chamamos de $\mathrm{X}$ e uma escola municipal que foi nomeada de Y para manter o anonimato de ambas. E os professores denominamos P1, P2, .., P37.

O projeto foi submetido e aprovado pelo comitê de ética da Universidade Alto Vale do Rio do Peixe e está registrado sob o número CAAE: 45329515.4.0000.5593.

O estudo foi desenvolvido dentro de uma perspectiva de análise qualitativa, considerando-se cinco categorias construídas a partir do referencial teórico: i) apropriação das TDIC pelos professores da educação básica; ii) a utilização das TDIC como parte integrante no Projeto Político Pedagógico da escola; iii) a inserção das tecnologias nos projetos dos professores; iv) a contribuição das TDIC para o processo de ensino e de aprendizagem e v) os desafios de utilização das TDIC pelos professores nas escolas.

\subsection{Participantes da pesquisa}

O questionário foi respondido por 37 professores das redes municipal e estadual de ensino de Caçador/SC. Quanto ao gênero, $81 \%$ dos participantes da pesquisa eram do sexo feminino, com idades variando entre 20 e 54 anos. Quanto ao nível de formação, $39 \%$ eram graduados; $58 \%$ especialistas e 3\% mestres e a maioria tinha entre 5 e 15 anos de docência nas escolas.

\subsection{Análise dos dados}

Os dados foram analisados a partir de cinco categorias, construídas com base nos dados e no referencial teórico, descritas a seguir.

\subsubsection{Categoria 1: Apropriação das TDIC pelos professores da educação básica.}

Nesta categoria analisamos a apropriação tecnológica e as possibilidades de uso das TDIC pelos professores na escola. Seguem trechos dos depoimentos de dois professores entrevistados:

P22. Ainda tenho muitas coisas a aprender sobre tecnologia, porém uso o que eu sei para trabalhar com os alunos, pois eles são natos na cultura digital.

P12. Somos resultado de uma prática pedagógica na qual não existiam muitas tecnologias, e quando utilizadas em sala de aula, era com o objetivo de recreação e não necessariamente como instrumento dos processos de ensino e aprendizagem.

Os professores ministram suas aulas da mesma maneira que aprenderam na escola e posteriormente nas licenciaturas, por isso é muito importante que os professores experienciem o uso da tecnologia.

Segundo Almeida e Valente (2011), é preciso privilegiar processos de formação que permitam o movimento da teoria à prática e vice-versa, levando o professor a perder o medo e a olhar para suas próprias práticas, desconstruí-las e construí-las a favor dos alunos, pois é preciso compreender a necessidade de ir além do currículo do lápis e do papel utilizado para representar e explicitar os conhecimentos dos alunos. 


\subsubsection{Categoria 2: A utilização das TDIC como parte integrante no Projeto Político Pedagógico da escola.}

Nesta categoria analisamos como a tecnologia é contemplada no projeto político pedagógico das escolas.

Consideramos inicialmente o projeto da escola municipal X.

PPP da escola X: A tecnologia vem para provocar mudanças pedagógicas, onde professores e estudantes têm a oportunidade de interação imediata [...]. Para tanto as tecnologias devem ser encaradas como um projeto que seja feito coletivamente e partilhado entre os diversos profissionais da unidade escolar. O poder e a influência só poderão ser revertidos em conhecimento escolar na medida em que forem aplicadas em conjunto e com reflexões compartilhadas.

E posteriormente da escola Y.

PPP da escola Y: A escola possui uma sala onde funciona o laboratório de informática. [...] contamos também com recursos tecnológicos, sendo 11 computadores, 3 impressoras, 1 rádio Microsystems, 1 caixa de som amplificada, 1 aparelho de DVD, 1 câmera digital, 1 televisão 29", uma televisão 21" e uma antena parabólica.

No PPP da escola X, a tecnologia é vista com o potencial de oportunizar mudanças na pratica pedagógica, oportunizando interação entre os alunos e professores. Já na escola $\mathrm{Y}$, podemos observar que a tecnologia é tratada como "materiais e equipamentos para auxiliar professores e estudantes no desenvolvimento de atividades pedagógicas dentro e fora da sala de aula".

Segundo Almeida e Prado (2005), durante muito tempo a inserção de tecnologias na escola direcionou-se à disponibilidade de equipamentos e softwares. Porém, evidenciou-se que isso não era suficiente para uma concreta inclusão de tecnologias à prática pedagógica dos professores, e que seria necessário envolver a escola como um todo, incluindo nesse processo a gestão da escola.

Muitas vezes a gestão da escola não reconhece a importância do uso de tecnologias, pois não participa das formações continuadas e das discussões pedagógicas, cuidando preferencialmente da parte administrativa da escola.

\subsubsection{Categoria 3: A inserção das tecnologias nos projetos dos professores .}

Nesta categoria, analisamos se os professores da educação básica estão utilizando as TDIC na construção de projetos.

Percebemos, pelas respostas ao questionário, que alguns professores realizam projetos com seus alunos em parceria com outros professores e/ou o professor do laboratório de informática.

P2. Sim, inclusive no encerramento do projeto água foi feito um cultural game com vídeos, jogos e fotos.

P18.Tínhamos um projeto com parceria do governo federal chamado UCA- Um Computador por Aluno onde, os alunos utilizavam 3 vezes por semana.

O papel do professor é fundamental tanto no sentido de criar e propor projetos, assim orientando no sentido de que os alunos trabalhem em cooperação com os colegas na construção de uma rede de aprendizagem. Vale ressaltar que, dentre os entrevistados em nossa pesquisa, alguns professores relatam que não trabalham com projetos. 
A este respeito, Gadotti (2007, p. 35) relembra que:

[...] vivemos hoje numa sociedade de redes e de movimentos, [...]. Torna-se fundamental aprender a pensar autonomamente, saber comunicar-se, saber pesquisar, saber fazer, ter raciocínio lógico, aprender a trabalhar colaborativamente, fazer sínteses e elaborações teóricas, saber organizar o próprio trabalho, ter disciplina, ser sujeito da construção do conhecimento, estar aberto a novas aprendizagens, conhecer as fontes de informação, saber articular o conhecimento com a prática e com outros saberes.

Segundo Ziede (2012), se houvesse um maior número de professores que trabalhassem com os alunos nos laboratórios com ambientes digitais de aprendizagem (blogs, wikis e outros), com simulações e com projetos de aprendizagem, nos quais os alunos desenvolvem inúmeras competências, certamente teríamos melhores resultados na educação básica. O papel do professor é fundamental para a inovação, pois não adianta usar a tecnologia sem uma mudança na metodologia.

\subsubsection{Categoria 4: A contribuição das tecnologias para os processos de ensino e aprendizagem.}

Nesta categoria a maioria dos participantes confirmou que as tecnologias podem auxiliar. Porém, em alguns enunciados de respostas percebemos o uso da tecnologia como mais um recurso apenas.

Analisando as respostas do questionário, $100 \%$ dos participantes disseram que sim, que as tecnologias podem auxiliar. Porém alguns ressaltaram que auxilia se for trabalhada de forma dinâmica e organizada

P2. Ela, hoje em dia, é fundamental na construção da aprendizagem, principalmente se a criança possuir alguma dificuldade cognitiva ou motora.

P23. Sim, de várias formas; pesquisas, leituras, jogos, atividades em geral que vem ao encontro ao que é trabalhado em sala de aula.

P24. Por que ao utilizar os tais programas e sites eles estarão aprendendo, desenvolvendo a criatividade e o processo de leitura e escrita.

Kenski (2014) assevera que o meio digital viabiliza múltiplas formas de acesso ao conhecimento. Quando o professor se apropria pedagogicamente destas formas, ele pode criar disciplinas e cursos que venham ao encontro das necessidades sociais e culturais atuais. "As especificidades dessa nova cultura digital colocam-se como desafios para a formação de professores e para a sua atuação profissional" (KENSKY 2014, p.13). As TDIC provocaram uma mudança na forma de compreensão tradicional do conhecimento, pois passaram de sequências lineares e previsíveis para hipertextos sem hierarquias, onde o aluno pode ir clicando e aprendendo de acordo com o seu ritmo e interesse.

\subsubsection{Categoria 5: Os desafios de utilização das TDIC pelos professores nas escolas.}

Nesta categoria, analisamos os desafios de utilização das TDIC pelos professores nas escolas de educação básica. 
Pelas falas dos professores e pelos estudos dos pesquisadores sobre o tema, percebemos que os desafios dos professores no uso da TDIC são os mesmos na maioria das escolas.

P6. O primeiro problema é que a escola não tem o número suficiente de computadores P13. Outro ponto é que a internet muitas vezes é lenta e falta de assistência.

P20. A principal dificuldade está no fato de que alguns professores de sala de aula ainda não têm capacitação necessária para preparar uma aula destinada a este fim, ou seja, não frequentam ou não tiveram interesse em participar de cursos voltados para este recurso, mesmo estes cursos sendo ofertados gratuitamente pelo órgão responsável pela educação digital, o NTE.

P22.Falta de conhecimento de alguns professores, medo do novo. Falta de equipamentos ou equipamentos desatualizados.

Há anos estamos ouvindo o mesmo discurso, enquanto os alunos participam de redes sociais, têm celulares com os quais produzem vídeos e fotos, escrevem mensagens, jogam e se comunicam com seus pares, porém, todo esse potencial é pouco utilizado nas escolas.

(1999.s/p).

Reforçando essa necessidade ratificamos o posicionamento de Fagundes

Conseguir alguns computadores é só o começo. Depois é preciso conectá-los à internet e desencadear um movimento interno de buscas e outro, externo, de trocas. Cabe ao professor, no entanto, acreditar que se aprende fazendo e sair da passividade da espera por cursos e por iniciativas da hierarquia administrativa.

Os desafios precisam ser vencidos e para que isto aconteça, os professores precisam refletir, agir, criar, inovar e principalmente perder o medo das TDIC.

\section{Discussão dos resultados}

As análises evidenciam, inicialmente, uma intenção dos professores em conhecer e se apropriar da tecnologia, entendendo seus limites e possiblidades. Nem tudo que eles planejam pode ser feito devido às condições dos equipamentos, do conhecimento técnico, ou mesmo pelo acesso aos laboratórios por parte dos alunos. Percebemos também que, mesmo a utilização das tecnologias digitais estando contemplada no projeto político pedagógico da escola, muitos professores não as utilizam. Alguns apontam que existem dificuldades de acesso à internet e algumas vezes os próprios professores pagam para os alunos poderem utilizar. Os computadores, muitas vezes antigos, não suportam os programas e travam, dificultando o desenvolvimento das atividades. Outra questão que dificulta a utilização das TDIC é a formação dos professores, que relatam ser o resultado de uma prática pedagógica na qual não existiam muitas tecnologias e, quando utilizadas em sala de aula, era com o objetivo de recreação e não necessariamente como instrumento de ensino e de aprendizagem. Alguns dos professores acreditam que as tecnologias auxiliam na avaliação, pois os alunos podem ser avaliados não apenas de forma tradicional, como geralmente é feito, mas de variadas formas, levando em consideração que cada aluno tem uma maneira particular de aprender e consequentemente de expor o 
que aprendeu. Muitos dos professores entrevistados não se sentem seguros para utilizar a tecnologia com seus alunos, alegando que eles são nativos digitais e apresentam maior fluência tecnológica. Concluímos que os professores vivenciam desafios constantes para integrar a tecnologia no currículo com propostas que privilegiem a autoria, a cooperação e o trabalho em rede.

\section{Considerações}

Esta pesquisa objetivou descrever se e como ocorre o uso de tecnologias por professores de escolas de educação básica de Caçador, SC, ficando patente que as tecnologias são consideradas importantes para as práticas de ensino e de aprendizagem. Ao grau de importância das TDIC, entretanto, não correspondem condições objetivas para a sua adoção e utilização concretas pelos professores - isto porque existem deficiências na esfera da formação dos professores e carências na infraestrutura das escolas. Esse binômio (deficiência/carência) ergue barreiras para uma utilização mais sistemática da TDIC nas salas de aula. Com isto, constata-se uma esquiva - ou mesmo fuga - dos professores no que se refere ao uso planejado das tecnologias, tendo como explicação a falta de formação anterior e preparo ou então a desculpa de que a natureza das mesmas era o mero passatempo, não se colocando como instrumentos para a construção de conhecimentos.

Cabe destacar que esta pesquisa apresenta um modesto poder de generalização em decorrência da quantidade de sujeitos envolvidos. No entanto, ele revela um pouco da complexidade, das perplexidades e das contradições que resultam das tentativas de aproximação entre as escolas - através dos professores - e as tecnologias. Revela também que temos um longo percurso a caminhar, caso queiramos construir uma escola do nosso tempo, uma escola em que os hábitos e costumes midiáticos dos estudantes sejam concretamente contemplados nos projetos políticos pedagógicos e assentados dinamicamente nos currículos e planos de ensino.

\section{Notas do texto}

A pesquisa do presente estudo foi apresentada no Congresso Ibero-Americano de Humanidades, Ciências e Educação UNESC - Universidade do Extremo Sul Catarinense - Criciúma 2016.

O estudo contou com a participação das graduandas Andreza de Oliveira Meireles da Silva (Bolsista FAP) e Aline Fernanda Wodonos de Carvalho (Bolsista Art. 170).

\section{Referências bibliográficas}

ALMEIDA, Maria Elizabeth Bianconcini; PRADO, Maria Elisabette Brisola Brito. Apresentação da série integração de tecnologias com as mídias digitais. In: Boletim do Salto para o Futuro. Brasília: MEC, SEED, 2005.

ALMEIDA, Maria Elizabeth B.; VALENTE, José A. Tecnologias e Currículo: trajetórias convergentes ou divergentes? São Paulo: Paulus, 2011.

ASSMANN, Hugo. Redes digitais e metamorfose do aprender. Petrópolis: Vozes, 2005.

BELLONI, Maria L. Educação a Distância. Campinas: Autores Associados, 2008. 
. O que é Mídia-Educação. Campinas: Autores Associados, 1995

BRASIL. Ministério da Educação. Secretaria de Educação Básica. Diretoria de Currículos e Educação Integral - DICEI. Coordenação Geral do Ensino Fundamental - COEF. Elementos conceituais e metodológicos para definição dos direitos de aprendizagem e desenvolvimento do ciclo básico de alfabetização $\left(1^{\circ}, 2^{\circ}\right.$ e $3^{\circ}$ anos $)$ do ensino fundamental. Brasília, DF: MEC, 2012. CETIC.br. TIC Educação 2014. Disponível em: $<$ http://cetic.br/noticia/formacaoeinfraestrutura-ainda-sao-barreiras-para-professoresconectados-indica-ticeducacao2014/>. Acesso em: 25. Out. 2016.

FAGUNDES, Léa. Revista Nova Escola, 1999.

GADOTTI, Moacir. A Escola e o Professor: Paulo Freire e a paixão de ensinar. São Paulo: Publisher Brasil, 2007.

KENSKI, Vani Moreira. Tecnologias e ensino presencial e a distância. Campinas, SP: Papirus, 2003.

. Tecnologias e tempo docente. Campinas, SP: Papirus, 2014.

LEMANN, Fundação. Conselho de Classe 2015. Disponível em: $<$ http://www.fundacaolemann.org.br/ conselho-de-classe/>. Acesso em: 25 out. 2016

LÉVY, Pierre. As Tecnologias da Inteligência. Rio de Janeiro: Editora 34, 1993.

MAÇADA, Débora Laurino; SATO, Luciane Sayuri; MARASCHIN, Cleci. Educação sem Distâncias: uma experiência de convivência em ambiente digital de aprendizagem. Revista Informática na Educação, Florianópolis, 2001. Disponível em:

http://www.nied.unicamp.br/oep/pub/art_ead_sem_dist_cleci_lec.pdf $>$. Acesso em: 12 nov. 2011.

MORAN, José Manuel. A educação que desejamos: novos desafios e como chegar lá. Editora Papirus Editora. Campinas 2007.

- Mudando a educação com metodologias ativas. Coleção Mídias Contemporâneas - Convergências Midiáticas, Educação e Cidadania: aproximações jovens (Volume II). SOUZA, Carlos Alberto de; e MORALES, Ofelia Elisa Torres (orgs.). PG: Foca Foto-PROEX/UEPG, 2015

- A educação que desejamos: novos desafios e como chegar lá. Editora Papirus Editora. Campinas 2007.

MORIN, Edgar. Educação com Consciência: edição revista e modificada. 8. ed. Rio de janeiro, 2005. Disponível em: $<\mathrm{http}$ ://ruipaz.pro.br/textos/cienciacomcon ciencia.pdf $>$. Acesso em: 10 nov. 2015.

ZIEDE, Mariangela Kraemer Lenz; ARAGÓN, Rosane. Docência no Ensino Superior: inovando e reconstruindo práticas pedagógicas na educação a distância. Currículo sem Fronteiras, v. 14, no 3, p. 254-279, 2014.

ZIEDE, Mariangela Kraemer Lenz. Alunos do Século 21. Jornal Zero Hora. Porto Alegre, p. 12 - 12, 03 set. 2012. 